\title{
EFFECT OF VARIOUS CUT-OUT ON BUCKLING ANALYSIS OF LAMINATED COMPOSITE PLATE USING FE SIMULATION
}

\author{
Rekha Shakya \\ Applied Mechanics Department \\ MNNIT, Allahabad, U.P., 211004 \\ shkya1989@gmail.com*
}

\author{
Tushar Sharma \\ Applied Mechanics Department \\ MNNIT, Allahabad, U.P., 211004 \\ tushar.sharma2412@gmail.com
}

\author{
Rajendra Bahadur \\ Applied Mechanics Department \\ MNNIT, Allahabad, U.P., 211004 \\ Rajendramech@gmail.com
}

\begin{abstract}
This paper investigate the buckling analysis of composite laminated plate with various cut-out (i.e., Elliptical-horizontal, Elliptical-vertical, Square, Rectangle, Circle, Diamond, Triangle) using FE simulation. The effect of buckling load on symmetric cross-ply $\left[(0 / 90)_{2}\right]_{s}$ and angle-ply $[(15 /-$ $\left.75)_{2}\right]_{\mathrm{s}},\left[(30 /-60)_{2}\right]_{\mathrm{s}}$ and $\left[(45 /-45)_{2}\right]_{\mathrm{s}}$ was determined on square composite laminate. These cut-outs are placed at the centre of the laminate. The buckling analysis is performed using FE simulation software Ansys 14.0 considering same area for all cut-outs. The effect of position of circular cut-out placed along the center line is also investigated. Results shows that ellipticalhorizontal and triangular cut-out give highest and lowest buckling load as compared to other cut-out, respectively. The results are validated with literature and show that cross-ply laminate give best result as compared to angle-ply laminate with irrespective of cut-out shape
\end{abstract}

Keywords-buckling, laminated composites, different cut-out, FEM

\section{INTRODUCTION}

There are many application of composite material like marine, mechanical, aerospace, and automotive industries in which they are used, reason behind this is because they are lighter and have high strength. Composite laminate can sustain much higher load under the action of various in-plane load, such as, uni-axial compression, in-plane shear and combined in-plane shear and compressive loads. Furthermore, cut-out are provided in these laminated structure because of various reasons, cut-outs to serve as doors and windows, ports for mechanical and electrical systems, holes for damage inspection, etc. It is necessary to understand the behavior of structural components such as buckling load, deflections, and modal characteristics, large deflection behavior, failure characteristics [1].
Ghannadpour et al. [2] performed buckling analysis of cross-ply laminated composite plate with circular/elliptical cutouts with two different boundary conditions, first case is simply supported on all edges, second case is clamped edge in unloaded edge and simply supported in loaded edge. They find that as circular cut-out diameter of square plate increases, buckling load will be decreased. They also find that buckling load with clamped boundary condition on unloaded edges is 2 times higher than the buckling load for the plate with simply supported boundary condition. Carle Pellegrino et al. [3] investigated linear and nonlinear behavior of steel plates with one hole (circular/rectangular), subjected to shear loading. The influence of the position with respect to two main axes, dimension, shape (rectangular/circular) and orientation of hole were also investigated. Kumar et al. [4] studied the effects of flexural boundary conditions on buckling and post-buckling behavior of axially compressed quasiisotropic laminate, $(+45 / 45 / 0 / 90)_{2 s}$ with various shaped cut-outs of various sizes using the finite element method. The FEM formulation is based on first order shear deformation theory and von Karman's assumptions are used to incorporate geometric nonlinearity. The 3-D Tsai-Hill criterion is used to predict the failure of a lamina while the onset of delamination is predicted by the inter-laminar failure criterion. Ovesy et al. [5] investigated effects of cutouts on the buckling critical stresses as well as natural frequencies. To predict the behavior of the moderately thick plates containing cutouts, A Reddy type, third order shear deformation theory of plates is applied to the development of two versions of finite strip method (FSM), namely semi-analytical and spline methods. Kumar et al. [6] studied stability and failure of a composite laminate with a centrally placed cutout of various shapes (i.e., circular, square, diamond, elliptical-vertical and elliptical-horizontal) under combined action of uni-axial compression and in-plane shear loads. The effects of cutout shape, direction of 


\section{ELK}

Asia Pacific Journals

shear load and composite lay-up on buckling and postbuckling responses, failure loads and failure characteristics of the laminate has been discussed. An efficient utilization of material strength is observed in the case of laminate with circular cutout as compared to the laminate with other shaped cutouts. Altan et al. [7] analysed buckling coefficients of symmetrically laminated reinforced concrete plates with a central rectangular hole under biaxial static compression loadings using finite element method. Composite structure of these plates has been constituted from four, six, eight and ten laminas including steel and concrete. The effect of change in central rectangular hole from the point view of size and direction on buckling coefficients is investigated in this study. Symmetrically laminated plates under biaxial in-plane loadings are taken into consideration in the analyses of simply supported and clamped boundary conditions. Obtained results are compared with each other according to $a / l$ and $b / l$ where $\mathrm{a}, \mathrm{b}$ are the hole sizes and 1 is the length of the plate, respectively. Arman et al. [8] performed effect of a single circular delamination around the circular hole on the critical buckling load of woven fabric laminated composite plates has been investigated experimentally and numerically. The determination of the critical delamination diameter for laminated composite plates has been intended by using three dimensional buckling analyses. For the experiments, cross-ply laminated composite plates with delamination and without delamination have been produced. The experimental critical buckling loads of plates have been found by clamping from the two edges and then these results have been compared with the results obtained from the numerical analyses. For the numerical analyses, ANSYS FEA program has been used. It has been seen that the numerical buckling analysis are very close to the experimental results. Komur et al. [9] analyzed buckling behavior of woven-glass-polyester laminated composite plate having an elliptical/circular cut-out using FEM. Parametric study is also carried out in this paper on various plates based on the shape and position of the elliptical hole. Ouinas et al. [10] studied buckling analysis of square plates with and without elliptical notch made of composite material using finite element method. The boron/epoxy laminated plates were arranged asymmetrically.

In this study, a buckling analysis was carried out for square laminated composite plate with various cut-out (i.e., Elliptical-horizontal, Elliptical-vertical, Square,
ISBN: 978-81-930411-4-7

Rectangle, Circle, Diamond, Triangle) located at centre using FE simulation. The plate is made of woven-glass polyester composite material. The effect of position of circular cut-out placed along the center line on buckling behavior is also investigated.

\section{FINITE ELEMENT MODEL}

\section{A. Element}

In the present study, Ansys 14.0 which is known general purpose finite element software was preferred as numerical tool. In this shell element were used which is SHELL281. This shell element is used for analyzing thin to moderately-thick shell structures. It is also used for layered applications for modeling laminated composite shells or sandwich construction. It is well-suited for large rotation, linear, and/or large strain nonlinear applications. The element has eight nodes with six degrees of freedom at each node: translations in the $x, y$, and $\mathrm{z}$ axes, and rotations about the $\mathrm{x}, \mathrm{y}$, and $\mathrm{z}$ axes.

\section{B. Material properties and Geometric model}

In this work, the laminated plates were taken into account having woven-glass fibers as reinforcement material and polyester as matrix material. The mechanical properties of the woven-glass-polyester composite material are listed in Table 1 [9]. In real composite applications, different plate and cutout form may be used owing to design necessities. Dimension of square composite plate considered is $120 \mathrm{~mm}$ x $120 \mathrm{~mm}$. The thickness of square composite plate is $1.6 \mathrm{~mm}$. The boundary condition apply to laminated plate is shown in Fig. 1.

Table 1. Mechanical properties of the woven-glasspolyester composite material

\begin{tabular}{|c|c|c|}
\hline $\begin{array}{l}\mathbf{E}_{\mathbf{1}}=\mathbf{E}_{\mathbf{2}} \\
(\mathbf{M P a})\end{array}$ & $\mathbf{G}_{\mathbf{1 2}}(\mathbf{M P a})$ & $v_{12}$ \\
\hline 31,610 & 3220 & 0.206 \\
\hline
\end{tabular}

To observe the buckling behavior of composite laminate plate with centrally placed cut-outs shape, cross-ply $\left[(0 / 90)_{2}\right]_{\mathrm{s}}$ and angle-ply $\left[(15 /-75)_{2}\right]_{\mathrm{s}},\left[(30 /-60)_{2}\right]_{\mathrm{s}}$, $[(45 /-$ $\left.45)_{2}\right]_{\mathrm{s}}$ laminates were used symmetrically. The major axes (b) and minor axes (c) of elliptical horizontal cutout are taken as 0.012 and 0.06 respectively. The area of cutouts considered in analysis is taken as same for all 


\section{ELK}

Asia Pacific Journals

cutout shapes and is equivalent to the area of the elliptical-horizontal cut-out. . Different cutout shapes details and their dimensions are given in Table 2. Furthermore, effect of positioning of circular cut-out along center line on buckling load is also studied in this work. The area of circle for this particular case is $1 / 30^{\text {th }}$ area of laminated plate.

Different model and mesh structure were made, because of different cut-outs shape. Among them, there is one model with boundary condition and loading condition is shown in fig.1.

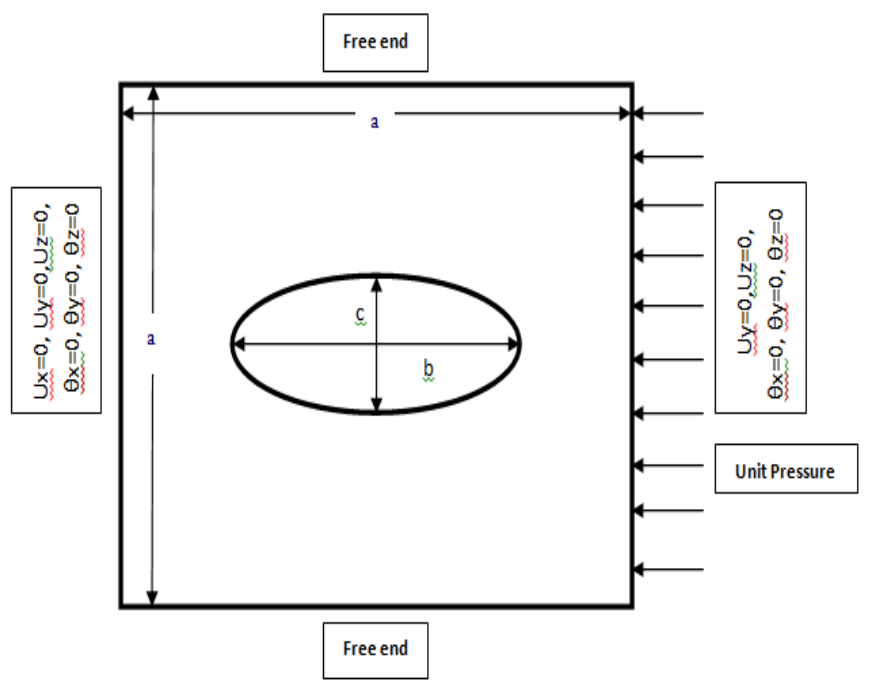

ELK Asia Pacific Journals - Special Issue ISBN: 978-81-930411-4-7

Fig.1. Geometry, boundary \& loading condition of the model

Table 2. Different cutout shapes and their dimensions.

\begin{tabular}{|l|l|}
\hline Cutout shapes & Cutout dimensions (in $\mathrm{mm}$ ) \\
\hline Elliptical horizontal & $\begin{array}{l}\text { Major axis=0.012, } \\
\text { Minor axis=0.06 }\end{array}$ \\
\hline Elliptical vertical & $\begin{array}{l}\text { Major axis }=0.06, \\
\text { Minor axis }=0.012\end{array}$ \\
\hline Rectangular & $\begin{array}{l}\text { length }=0.06726, \\
\text { width }=0.03363\end{array}$ \\
\hline Square & Each side $=0.04756$ \\
\hline Circular & Radius $=0.0268$ \\
\hline Diamond & $\begin{array}{l}\text { Same as square just rotate } \\
45^{0}\end{array}$ \\
\hline Triangular & $\begin{array}{l}\text { base }=0.07227, \\
\text { height }=0.06259\end{array}$ \\
\hline
\end{tabular}

Table 3. Buckling load results with stacking sequences for elliptical horizontal and vertical cut-outs

\begin{tabular}{|c|c|c|c|c|c|c|c|c|}
\hline & \multicolumn{3}{|c|}{$\begin{array}{r}\mathrm{b} / \mathrm{a}=0.5, \mathrm{c} / \mathrm{a}=0.1, \\
\alpha=0^{0}\end{array}$} & \multicolumn{2}{c|}{$\mathrm{b} / \mathrm{a}=0.4, \mathrm{c} / \mathrm{a}=0.2, \alpha=0^{0}$} & \multicolumn{2}{c|}{$\mathrm{b} / \mathrm{a}=0.3, \mathrm{c} / \mathrm{a}=0.2, \alpha=0^{0}$} & \multicolumn{2}{|c|}{$\begin{array}{c}\mathrm{b} / \mathrm{a}=0.5, \mathrm{c} / \mathrm{a}=0.1, \\
\alpha=90^{0}\end{array}$} \\
\hline $\begin{array}{c}\text { Stacking } \\
\text { Sequence }\end{array}$ & $\begin{array}{c}\text { Paper } \\
\text { result }\end{array}$ & Ref [9] & $\begin{array}{c}\text { Present } \\
\text { result }\end{array}$ & Ref [9] & $\begin{array}{c}\text { Present } \\
\text { result }\end{array}$ & Ref [9] & $\begin{array}{c}\text { Present } \\
\text { result }\end{array}$ & Ref [9] \\
\hline$(0 / 90)_{2 \mathrm{~s}}$ & 27.3279 & 27.3279 & 26.8142 & 25.5285 & 27.0715 & 25.6911 & 21.3457 & 20.1215 \\
\hline$(15 /-75)_{2 \mathrm{~s}}$ & 23.6842 & 23.6842 & 21.8233 & 22.5203 & 22.5122 & 23.1707 & 17.9382 & 17.8543 \\
\hline$(30 /-60)_{2 \mathrm{~s}}$ & 19.2308 & 19.2308 & 17.4165 & 18.5366 & 17.9194 & 18.6179 & 14.9614 & 15.1822 \\
\hline$(45 /-45)_{2 \mathrm{~s}}$ & 17.6113 & 17.6113 & 16.1759 & 16.9919 & 16.304 & 16.3415 & 13.8447 & 14.2105 \\
\hline
\end{tabular}

\section{RESULT \& DISCUSSION}

In this work, Convergence test of mesh size is done on plate with elliptical hole having dimension as $\mathbf{b} / \mathbf{a}=\mathbf{0 . 4}$, $\mathbf{c} / \mathbf{a}=\mathbf{0 . 2}, \boldsymbol{\alpha}=\mathbf{0}^{\mathbf{0}}$. No. of element on each side of plate is varied from 10 to 70 according to which size of element
$\&$ total no. of element in plate decreases \& increases respectively. In the first part, the result is validated with Komur et.al [9] as shown in Table.3. In this table result were validated for elliptical-horizonal cut-out and elliptical-vertical cut-out for symmetrically cross-ply $\left[(0 / 90)_{2}\right]_{\mathrm{s}}$ and angle-ply $\left[(15 /-75)_{2}\right]_{\mathrm{s}},\left[(30 /-60)_{2}\right]_{\mathrm{s}}$, $[(45 /-$ 


\section{ELK}

Asia Pacific Journals

$\left.45)_{2}\right]_{\mathrm{s}}$ laminates. The effect of horizontal and vertical elliptical cut-out on buckling load with $\left[(0 / 90)_{2}\right]_{\mathrm{s}}$ ply is shown in fig. 2.
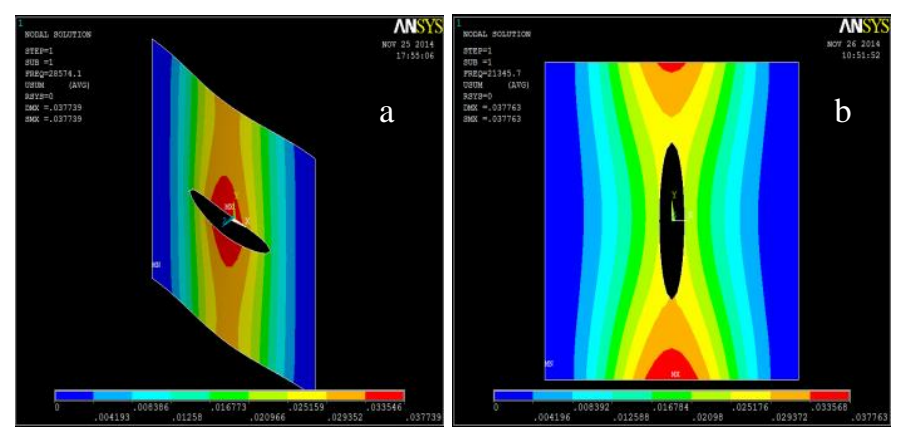

Fig.2. Effect of (a) Elliptical-horizontal \& (b) Ellipticalvertical cut-out on buckling load

The effect of different cut-out shape on buckling load for different stacking sequence is shown in Fig. 3. In case of $\left[(0 / 90)_{2}\right]_{s}$ cross-ply laminate, steep decrement in buckling load between elliptical horizontal and rectangular cut-out, and also between circular and diamond cut-out as shown in fig.3. The ellipticalhorizontal cut-out give higher value and triangular cutout give lower value. In this case except these two, other cut-out have closer value. In case of $\left[(15 /-75)_{2}\right]_{s}$ laminate, there are high difference of buckling load between elliptical horizontal and rectangular cut-out, and all other cut-out have almost close value. In case of angle ply $\left[(30 /-60)_{2}\right]_{\mathrm{s}}, \quad\left[(45 /-45)_{2}\right]_{\mathrm{s}}$ laminates, from rectangle to diamond cut-out there are closer value of buckling load. The difference between buckling loads among all these laminates $\left[(0 / 90)_{2}\right]_{s}$ cross-ply laminate give highest buckling load as comparison to all other laminates. In each case of laminate, elliptical horizontal cut-out give maximum buckling load and triangular cutout give

minimum buckling load. From rectangular to diamond cut-out, there are closer value of buckling load for angleply $\left[(15 /-75)_{2}\right]_{\mathrm{s}}, \quad\left[(30 /-60)_{2}\right]_{\mathrm{s}}, \quad\left[(45 /-45)_{2}\right]_{\mathrm{s}}$ laminates, whereas decrement is occurred with high value from circular to diamond cut-out. Furthermore, the buckling

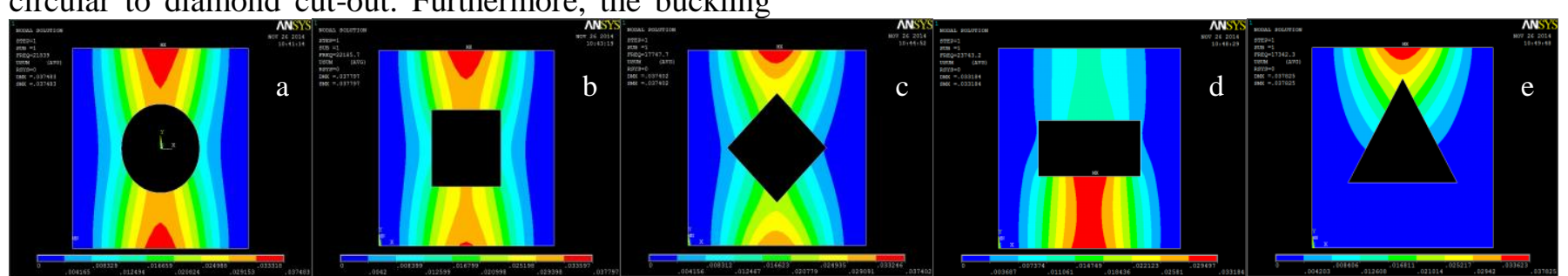

Fig. 5. Nodal solution result for (a) Circular, (b) Square, (c) Diamond, (d) rectangular \& (e) Triangular cut-out
ELK Asia Pacific Journals - Special Issue ISBN: 978-81-930411-4-7

load of all cut-out shape give closer value for [(30/$\left.60)_{2}\right]_{\mathrm{s}}$, [(45/-45 $\left.)_{2}\right]_{\mathrm{s}}$ laminates, and much closer value obtained for triangular cut- out. Meanwhile diamond cutout give much closer value for cross-ply $\left[(0 / 90)_{2}\right]_{\mathrm{s}}$ and angle-ply $\left[(15 /-75)_{2}\right]_{\mathrm{s}}$, laminates. The highest value of buckling load are calculated for $\left[(0 / 90)_{2}\right]_{\mathrm{s}}$ plates, while the lower values are computed for angle-ply $\left[(45 /-45)_{2}\right]_{s}$. In other words cross-ply $\left[(0 / 90)_{2}\right]_{s}$ plates give best results as comparison to all other angle-ply.

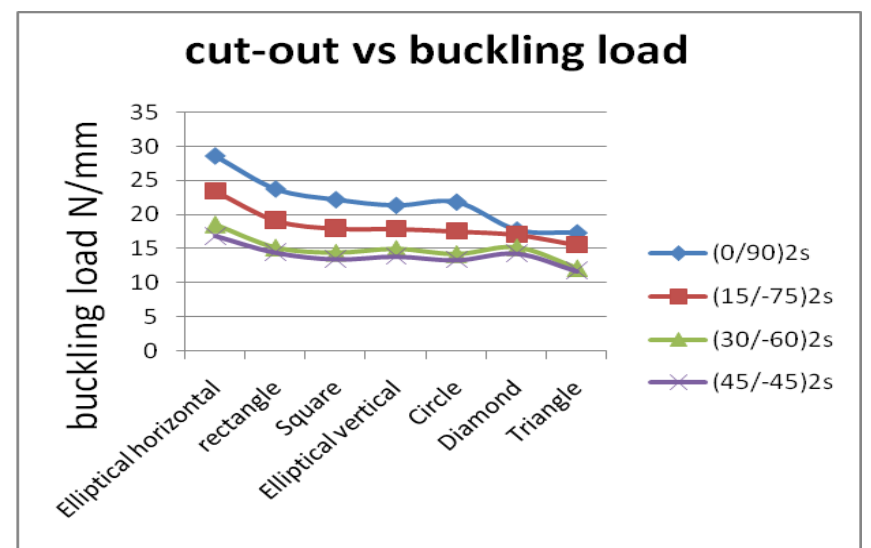

Fig. 3. Effect of different cut-out on buckling load

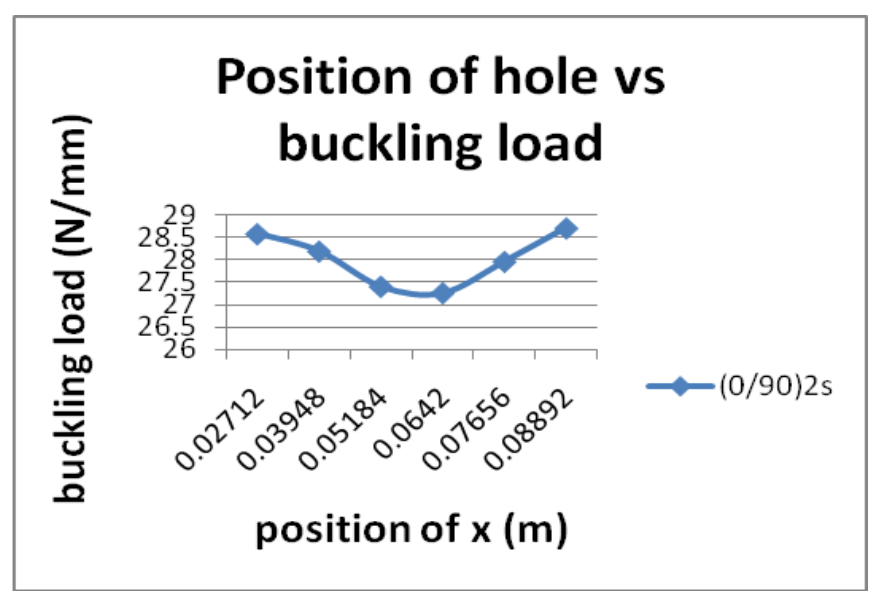

Fig. 4. Effect of positioning of circular cutout on buckling load 
ELK

Asia Pacific Journals

The effect of different cut-out on nodal solution calculate from FE simulation software Ansys for $\left[(0 / 90)_{2}\right]_{s}$ ply is shown in Fig. 5.

The effect of positioning of circular cut-out along $\mathrm{x}$-axis on buckling load is also investigated. For this analysis square plate with circular cutout is selected, and Circular hole is moved from left to right on central line for $\left[(0 / 90)_{2}\right]_{s}$ plates. In the centre of plate buckling load value is lowest as shown in fig. 4 . As the circular hole is moved apart from centre buckling load increases, it means it strength increases as position of circular cut-out moved away from centre.

\section{CONCLUSIONS}

In this paper, buckling response of square composite laminated plate with various cut-out (i.e., Ellipticalhorizontal, Elliptical-vertical, Square, Rectangle, Circle, Diamond, Triangle) made of woven-glass-polyester composite material using FE simulation is investigated. These cut-outs are placed at the centre of the laminate. The buckling analysis is performed using FE simulation software Ansys 14.0 considering same area for all cutouts. The effect of position of circular cut-out placed along the center line is also investigated.

Based on result of present investigation, following important conclusions can be drawn:

- Stacking sequence $(0 / 90)_{2 \mathrm{~s}}$, have maximum buckling load on comparing with other stacking sequences.

- Laminate with elliptical horizontal cutout have maximum buckling load, while laminate with triangular cut-out have minimum buckling load.

- Triangular cut-out and rectangular cut-out give much closer value for angle-ply $\left[(30 /-60)_{2}\right]_{\mathrm{s}},\left[(45 /-45)_{2}\right]_{\mathrm{s}}$ laminates.

- Diamond cut-out give much closer value for crossply $\left[(0 / 90)_{2}\right]_{\mathrm{s}}$ and angle-ply $\left[(15 /-75)_{2}\right]_{\mathrm{s}}$, laminates.

- Buckling load increases as the circular cut-out moves from centre to edges, means laminate plate is weaker in centre of plate and as the circular cut-out moved away from centre it strength increases.

\section{REFERENCES}

[1] YH Zhang, CH Yang, "Recent developments in finite element analysis for laminated composite plates," Compos Struct, vol. 88, pp. 147-57, 2009.

[2] S.A.M. Ghannadpour, A. Najafi, B. Mohammadi, "On the buckling behaviour of cross-ply laminated composite plates due to circular/elliptical cutouts," Composite Structures, vol. 75, pp. 3-6, 2006.
ELK Asia Pacific Journals - Special Issue

\section{ISBN: 978-81-930411-4-7}

[3] Carle Pellegrino, Emanuele Maiorana, "Claudio Modena. Linear and non-linear behaviour of steel plates with circular and rectangular holes under shear loading," J.Thin-Walled Structures, vol. 47, pp. 6076162009 .

[4] Dinesh Kumar, S.B Singh, "Effect of boundary condition on buckling and post-buckling responses of composite laminate with various shaped cut-outs," J.Composite Structure, vol. 92, pp. 769-779 2010.

[5] H.R Ovesy, j. Fazilati, "Buckling and free vibration strip analysis of composite plates with cutout based on two different modeling approach," J.Composite Structures, vol. 94, pp. 1250-1258, 2012.

[6] Dinesh Kumar, S.B.Singh, "Stability and failure of composite laminate with various shaped cut-outs under combined in-plane loads," J.Composite, vol. Part B 43, pp. 142-149, 2012.

[7] Mehmet Fatih Altan, and Murat Emre Kartal, "Investigation of buckling behavior of laminated reinforced concrete plates with central rectangular hole using finite element method," Materials and Design, vol. 30, pp. 2243-2249, 2009.

[8] Yusuf Arman, Mehmet Zor, Sami Aksoy, "Determination of critical delamination diameter of laminated composite plates under buckling loads," Composites Science and Technology, vol. 66, pp. 2945-2953, 2006.

[9] M. Aydin Komur, Faruk Sen , Akın Atas Nurettin Arslan,"Bucklinganalysis of laminated composite plates with an elliptical/circular cutout using FEM," Advances in Engineering Software, vol. 41, pp. 161-164, 2010.

[10] Djamel Ouinas, Belkacem Achour, "Buckling analyșis of laminatedcomposite plates [(h/h)] containing an elliptical notch," Composites, vol. Part B 55, pp. 575-579, 2013. 